\title{
Activation of Group III Metabotropic Glutamate Receptors Inhibits the Production of RANTES in Glial Cell Cultures
}

\author{
Gilbert Besong, ${ }^{1 *}$ Giuseppe Battaglia, ${ }^{\text {* }}$ Mara D'Onofrio, ${ }^{1 *}$ Roberto Di Marco, ${ }^{2}$ Richard Teke Ngomba, ${ }^{1}$ \\ Marianna Storto, ${ }^{1}$ Marzia Castiglione, ${ }^{4}$ Katia Mangano, ${ }^{2}$ Carla L. Busceti, ${ }^{1}$ Ferdinando R. Nicoletti, ${ }^{2,3}$ \\ Kevin Bacon, ${ }^{5}$ Michael Tusche, ${ }^{5}$ Ornella Valenti, ${ }^{6}$ Peter Jeffrey Conn, ${ }^{6}$ Valeria Bruno, ${ }^{1,4}$ and \\ Ferdinando Nicoletti ${ }^{1,4}$
}

1/stituto Neurologico Mediterraneo Neuromed, 86077 Pozzilli, Italy, Departments of 2Microbiology and Gynecology and ${ }^{3}$ Biology/Section of General Pathology, University of Catania, 95125 Catania, Italy, ${ }^{4}$ Department of Human Physiology and Pharmacology, University "La Sapienza”, 00185 Rome, Italy, ${ }^{5}$ Department of Biology, Bayer Yakuhin, Ltd. 6-5-1-3, Kunimidai, Kyoto, Japan, and 'Department of Pharmacology, School of Medicine, Emory University, Atlanta, Georgia 30322

The chemokine RANTES is critically involved in neuroinflammation and has been implicated in the pathophysiology of multiple sclerosis. We examined the possibility that activation of G-proteincoupled metabotropic glutamate (mGlu) receptors regulates the formation of RANTES in glial cells. A $15 \mathrm{hr}$ exposure of cultured astrocytes to tumor necrosis factor- $\alpha$ and interferon- $\gamma$ induced a substantial increase in both RANTES mRNA and extracellular RANTES levels. These increases were markedly reduced when astrocytes were coincubated with L-2-amino-4-phosphonobutanoate (L-AP-4), 4-phosphonophenylglycine, or L-serine-Ophosphate, which selectively activate group III mGlu receptor subtypes (i.e., mGlu4, $-6,-7$, and -8 receptors). Agonists of mGlu1/5 or mGlu2/3 receptors were virtually inactive. Inhibition of RANTES release produced by L-AP-4 was attenuated by the selective group III mGlu receptor antagonist $(R, S)$ - $\alpha$-methylserine$O$-phosphate or by pretreatment of the cultures with pertussis toxin. Cultured astrocytes expressed mGlu4 receptors, and the ability of L-AP-4 to inhibit RANTES release was markedly reduced in cultures prepared from mGlu4 knock-out mice. This suggests that activation of mGlu4 receptors negatively modulates the production of RANTES in glial cells. We also examined the effect of L-AP-4 on the development of experimental allergic encephalomyelitis $(E A E)$ in Lewis rats. L-AP-4 was subcutaneously infused for $28 \mathrm{~d}$ by an osmotic minipump that released $250 \mathrm{nl} / \mathrm{hr}$ of a solution of $250 \mathrm{~mm}$ of the drug. Detectable levels of L-AP-4 ( 100 $\mathrm{nM})$ were found in the brain dialysate of EAE rats. Infusion of L-AP-4 did not affect the time at onset and the severity of neurological symptoms but significantly increased the rate of recovery from EAE. In addition, lower levels of RANTES mRNA were found in the cerebellum and spinal cord of EAE rats infused with L-AP-4. These results suggest that pharmacological activation of group III mGlu receptors may be useful in the experimental treatment of neuroinflammatory CNS disorders.

Key words: chemokines; glial cultures; experimental allergic encephalomyelitis; multiple sclerosis; mGlu4 receptor; leukocytes
Chemokines constitute a growing family of low molecular weight cytokines $(8-14 \mathrm{kDa})$ that play a pivotal role in many biological processes, from routine immunosurveillance to the control of inflammation and cell infection by human immunodeficiency virus. They are divided into four distinct subfamilies (designated as $\alpha$ or $\mathrm{CXC}, \beta$ or $\mathrm{CC}, \gamma$ or $\mathrm{CX} 3 \mathrm{C}$, and $\delta$ or $\mathrm{C}$ chemokines) and activate G-protein-coupled receptors, which are named according to the classification of their specific ligands (Bazan et al., 1997; Pan et al., 1997; Wells et al., 1998). Chemokines have been implicated in the modulation of numerous biological functions in both the developing and mature CNS, including neuropoiesis, oligodendrocyte proliferation, regulation of synaptic plasticity, and, particularly, leukocyte recruitment in response to traumatic injury, stroke, autoimmunity, and inflammation (Mennicken et

\footnotetext{
Received Nov. 12, 2002; revised April 4, 2002; accepted April 11, 2002.

*G.B., G.B., and. M.D. contributed equally to this work.

Correspondence should be addressed to Dr. Ferdinando Nicoletti, Department of Human Physiology and Pharmacology, University of Rome "La Sapienza", Piazzale Aldo Moro, 5, 00185 Rome, Italy. E-mail: nicoletti@neuromed.it.

Copyright (C) 2002 Society for Neuroscience $0270-6474 / 02 / 225403-09 \$ 15.00 / 0$
}

al., 1999). Chemokines are the only group of inflammatory mediators endowed with cell type-selective chemotactic activity, and hence, they play a vital role in defining the cellular composition of inflammatory infiltrates at the sites of tissue damage. Because of this, chemokines are becoming potential targets for therapeutic intervention in inflammatory disorders of the CNS, including multiple sclerosis (MS) (Godiska et al., 1995; Miyagishi et al., 1997; Ransohoff and Bacon, 2000) (see Discussion and references therein). Chemokines are constitutively expressed at low-tonegligible levels in neurons, astrocytes, and microglia, but are markedly upregulated in response to proinflammatory cytokines, such as tumor necrosis factor- $\alpha$ (TNF- $\alpha$ ) and interferon- $\gamma$ (IFN- $\gamma$ ) (Barnes et al., 1996; Mennicken et al., 1999). The identification of membrane receptors that control the induction of chemokines is an obligatory step in the search for drugs acting on leukocyte recruitment in neuroinflammation. We now report that pharmacological activation of group III mGlu receptors reduces the synthesis and release of the $\beta$-chemokine RANTES (from regulated upon activation of normal $\mathrm{T}$ cell expressed and secreted) induced by TNF- $\alpha$ and IFN- $\gamma$ in cultured astrocytes and increases the rate of functional recovery in an in vivo model of neuroinflammation. 


\section{MATERIALS AND METHODS}

Materials. (S)-4-carboxy-3-hydroxyphenylglicine (4C3HPG), L-2-amino4-phosphonobutanoate (L-AP-4), $(R, S)$ - $\alpha$-methylserine- $O$-phosphate (MSOP), L-serine- $O$-phosphate (L-SOP), (RS)-3,5-dihydroxyphenylglycine (DHPG), and $(2 R, 4 R)$-4-aminopyrrolidine-2,4-dicarboxylate $(2 R, 4 R$ APDC) were purchased from Tocris Cookson Ltd. (Bristol, UK). 4-phosphonophenylglycine (PPG) was a generous gift from Dr. Peter J. Flor and Dr. Fabrizio Gasparini (Novartis Pharma, Basel, Switzerland). All other drugs or chemicals were purchased from Sigma (Milan, Italy).

Preparation of primary cultures of mouse or rats cortical astrocytes. Primary cultures of cortical astrocytes were prepared from neonate CD1 mice (Charles River, Calco, Italy), mGlu4 knock-out mice (Jackson Laboratories, Bar Harbor, MN), or Lewis rats (Charles River), as described by Rose et al. (1992). Dissociated cortical cells were grown in MEM-Eagle's salts, supplemented with $10 \%$ horse serum, $10 \%$ fetal calf serum, $2 \mathrm{~mm}$ glutamine, $25 \mathrm{~mm}$ sodium bicarbonate, and $21 \mathrm{~mm}$ glucose. Cultures were kept at $37^{\circ} \mathrm{C}$ in a humidified $5 \% \mathrm{CO}_{2}$ atmosphere until they reached confluence (7-14 $\mathrm{d}$ in vitro). The number of microglial cells contaminating the cultures was assessed in cultures fixed with $2 \%$ paraformaldehyde by using the lectin, isolectin $\mathrm{B}_{4}$ Banderiera simplicifolia I, coupled to biotin. After $30 \mathrm{~min}$ of incubation at room temperature with lectin at 1:50 dilution, lectin binding was identified by using the $\mathrm{ABC}$ Vectastain kit (Vector Laboratories, Burlingame, CA). The efficacy of the method for the detection of microglial cells was proven by staining spinal cord sections of Lewis rats $11 \mathrm{~d}$ after immunization with myelin basic protein (MBP) (data not shown).

Measurement of extracellular RANTES in the glial medium. Glial cultures were washed with serum-free medium and, $1 \mathrm{hr}$ later, were incubated for $15 \mathrm{hr}$ with IFN- $\gamma(10 \mathrm{U} / \mathrm{ml})$ and TNF- $\alpha(0.1 \mathrm{ng} / \mathrm{ml})$, in the absence or presence of specific mGlu receptor ligands. At the end of the incubation, the medium was removed and used for the determination of RANTES using the mouse RANTES QUANTIKINE M immunoassay ELISA kit (R \& D Systems, Minneapolis, MN).

$R N A$ extraction and Northern blot analysis of RANTES $m R N A$. Total RNA was prepared from cultured astrocytes and from cerebellum and spinal cord of Lewis rats (Chomczynski and Sacchi, 1987). Thirty micrograms of total RNA were denatured, subjected to electrophoresis on $1 \%$ formaldehyde agarose gel, and transferred to a nylon membrane Hybond-N (Amersham Pharmacia Biotech, Milan, Italy). Membranes were fixed by UV irradiation using an XL-1500 UV cross-linker (Spectrolinker, Spectronics Corporation, Westbury, NY) and stained with $0.04 \%$ methylene blue and $0.5 \mathrm{~m}$ sodium acetate. Membranes were hybridized with a random primed $\left[\alpha-{ }^{32} \mathrm{P}\right]$-dCTP-labeled probe consisting of RANTES $0.7 \mathrm{~kb}$ cDNA insert in a pCR II vector (Invitrogen, Groningen, The Netherlands) cloned at the BstXI/NotI site. Hybridizations were performed overnight at $42^{\circ} \mathrm{C}$. Blots were washed twice using $2 \times \mathrm{SSC}-0.1 \%$ SDS for $15 \mathrm{~min}$ at $42^{\circ} \mathrm{C}$ and then twice with $0.1 \times$ SSC $-0.1 \%$ SDS for $15 \mathrm{~min}$ at $42^{\circ} \mathrm{C}$. The filters were then exposed to Hyperfilm-MP (Amersham Pharmacia Biotech) and exposed at $-80^{\circ} \mathrm{C}$ for $18 \mathrm{hr}$. Filters were reprobed with $\beta$-actin cDNA, and autoradiograms were quantified by densitometry using a computerized image-processing system (NIH Imaging, Bethesda, MD).

RT-PCR analysis of mGlu4 receptors. Two micrograms of total RNA extracted from cultured astrocytes and $100 \mathrm{ng}$ of random hexamers dissolved in $10 \mu \mathrm{l}$ of RNase-free water were heated to $65^{\circ} \mathrm{C}$ for $10 \mathrm{~min}$ and then cooled on ice. Reverse transcriptase (RT) buffer (10 mM DTT, $500 \mu \mathrm{M} \mathrm{dNTP}$, and $200 \mathrm{U}$ of Moloney murine leukemia virus RT enzyme) was added to a final volume of $25 \mu$ l. The incubation was continued at $42^{\circ} \mathrm{C}$ for $1 \mathrm{hr}$, and the reaction was terminated by a $10 \mathrm{~min}$ incubation at $99^{\circ} \mathrm{C}$. PCR was performed for 35 cycles in final volume of $50 \mu \mathrm{l}$ with appropriate quantity of buffer and $\mathrm{MgCl}_{2}, 200 \mu \mathrm{M}$ of dNTP, $50 \mathrm{pmol}$ of either forward or reverse primers, and $2.5 \mathrm{U}$ of AmpliTaq Gold (Perkin-Elmer Cetus Corp., Norwalk, CT). RT-PCR negative control was performed loading $\mathrm{dH}_{2} \mathrm{O}$ instead of cDNA. Primers and PCR conditions were as follows: mGlu4 receptor: GenBank accession \#M90518; $1.5 \mathrm{mM} \mathrm{MgCl}_{2}$; annealing at $60^{\circ} \mathrm{C}$; amplimer $567 \mathrm{bp}$; forward: 5'-TGAGCTACGTGCTGCTGGCG-3'; reverse: 5'-TGTCGGCTGACTGTGAGGTG-3'.

Western blot analysis of RANTES and mGlu4 receptors. Western blot analysis in protein extracts from lysates of cultured astrocytes prepared from mice or rats or from mouse cerebral cortex (used as a positive control) was performed as described by Ciccarelli et al. (2000). RANTES expression was detected with $4 \mu \mathrm{g} / \mathrm{ml}$ of a monoclonal antibody (R \& D Systems). mGlu4a receptors were detected with $0.5 \mu \mathrm{g} / \mathrm{ml}$ of a polyclonal antibody raised against synthetic peptides corresponding to the following amino acid sequences CGGLETPALATKQTYVTNHAI corresponding to the putative intracellular C-terminal domain of rat mGlu4a receptor (Upstate Biotechnology, Inc. Lake Placid, NY; residues 893-912) (Bradley et al., 1996, 1999).

Induction of experimental allergic encephalomyelitis in Lewis rats. For experimental allergic encephalomyelitis (EAE) induction, Lewis rats (225-250 gm, body weight) were immunized in the proximal portion of the tail with $50 \mu \mathrm{g}$ of guinea pig MBP, $2 \mathrm{mg}$ Mycobacterium tuberculosis in $100 \mu \mathrm{l}$ saline, and $100 \mu \mathrm{l}$ Freund's incomplete adjuvant. Animals were implanted with subcutaneous osmotic minipumps (Alzet; Alza, Palo Alto, CA) containing $200 \mu \mathrm{l}$ of $250 \mathrm{~mm}$ of L-AP-4 dissolved in PBS, which release $250 \mathrm{nl} / \mathrm{d}$ for $28 \mathrm{~d}$. Control animals were implanted with minipumps containing PBS alone. Immunization was performed $48 \mathrm{hr}$ after implanting the osmotic minipumps. In standard experiments, immunized animals developed clinical signs of EAE $10 \mathrm{~d}$ after immunization. Symptoms of EAE were scored using the disability scale described by Godiska et al. (1995) in which $0=$ absence of clinical signs; $1=$ loss of motor control in the tail; $2=$ hindquarter weakness or the inability to turn over when placed on the back; $3=$ total hindquarter paralysis; $4=$ total hindquarter paralysis with incontinence and/or forearm involvement; and 5 = death caused by EAE. In addition, body weight was monitored every day during the development of EAE.

Some animals were killed $12 \mathrm{~d}$ after immunization (i.e., at the time of the peak of clinical symptoms) for the detection of RANTES in the cerebellum and spinal cord. RANTES protein and mRNA levels were assessed by Western and Northern analysis, as described above.

Immunohistochemical analysis of spinal cords. Two established parameters of neuroinflammation, i.e., the expression of major histocompatibility complex (MHC) class II antigens and the presence of $\mathrm{CD}^{+}$cells were examined by immunohistochemistry in Lewis rats immunized with MBP and treated with L-AP-4, as described above. Animals were killed by $\mathrm{CO}_{2}$ inhalation at 11 or $27 \mathrm{~d}$ after immunization, and spinal cords were collected and snap-frozen in liquid nitrogen. For immunohistochemical analysis, spinal cord cryostat sections $(10 \mu \mathrm{m})$ were exposed to appropriate dilutions of the mouse FITC-conjugated monoclonal antibodies (Seralab, Crawley-Down, UK) directed against the rat homologs of human CD4, (W3/25), and MHC class II antigens (OX6). Coded slides were examined by fluorescence microscopy at $40 \times$ magnification. Inflammation grade was assessed blindly and scored from grade 1-4 in relation to the intensity of immunostaining, density of immunopositive cells, and distribution of clusters of immunopositive cells (total score: $0-12$ ) (Di Marco et al., 2001).

Measurements of L-AP-4 levels by in vivo microdialysis. To assess whether subcutaneously infused L-AP-4 can penetrate the brain, we measured the amount of the drug present in the striatal dialysate of freely moving animals. Lewis rats, $250-300 \mathrm{gm}$, were implanted with microdialysis intracerebral guides in the striatum using the following coordinates: $2.0 \mathrm{~mm}$ anterior to bregma, $2.6 \mathrm{~mm}$ lateral to the midline, and 4-6 $\mathrm{mm}$ ventral, according to the atlas of Pellegrino et al. (1992), under pentobarbital anesthesia $(50 \mathrm{mg} / \mathrm{kg}$, i.p.). After surgery, rats were housed in separate cages in a temperature-controlled environment on a $12 \mathrm{hr}$ light/dark cycle, with ad libitum access to water and food, and allowed to recover. Forty-eight hours later rats were implanted with subcutaneous osmotic minipumps (Alzet), containing L-AP-4 (200 $\mu \mathrm{l}, 250 \mathrm{~mm})$ that release $250 \mathrm{nl} / \mathrm{d}$ for $28 \mathrm{~d}$ of L-AP-4, and were immunized $48 \mathrm{hr}$ later as described above. Microdialysis was performed $9 \mathrm{~d}$ after immunization. Twelve hours before the experiment, a concentric vertical probe $(2-\mathrm{mm}$ long and $0.5 \mathrm{~mm}$ in outer diameter having a polycarbonate membrane; molecular cutoff: 20,000 Da; CMA/12; CMA Microdialysis, Stockholm, Sweden) was inserted into the intracerebral guide cannula, and rats were transferred to a plastic bowl cage with a moving arm. The animals had ad libitum access to water and food. The probe was perfused continuously with artificial CSF (ACSF), at a flow rate of $0.1 \mu \mathrm{l} / \mathrm{min}$, using a microinjection pump. ACSF contained in mM: $150 \mathrm{NaCl}, 3 \mathrm{KCl}, 1.7 \mathrm{CaCl}_{2}$, and $0.9 \mathrm{MgCl}_{2}$. On the next day, perfusate sample fractions were continuously collected by a fraction collector. Analysis of L-AP-4 present in the dialysate was performed by HPLC with fluorescence detection.

Measurement of extracellular RANTES in leukocytes. Peripheral blood mononuclear cells (PBMCs) were prepared using Ficoll HyPaque according to the manufacturer's recommended protocol. Enriched monocytes were obtained from whole PBMCs by incubation with RPMI 1640 $+10 \% \mathrm{FCS}$ at $4^{\circ} \mathrm{C}$, for $30 \mathrm{~min}$ at constant rotation. Nonaggregated cells were removed, and monocyte-enriched pellet was resuspended in RPMI and plated $2 \times 10^{-6}$ cells per well in 6 -well plates. After a $2 \mathrm{hr}$ incubation at $37^{\circ} \mathrm{C}$, nonadherent cells were removed, and adherent cells were 

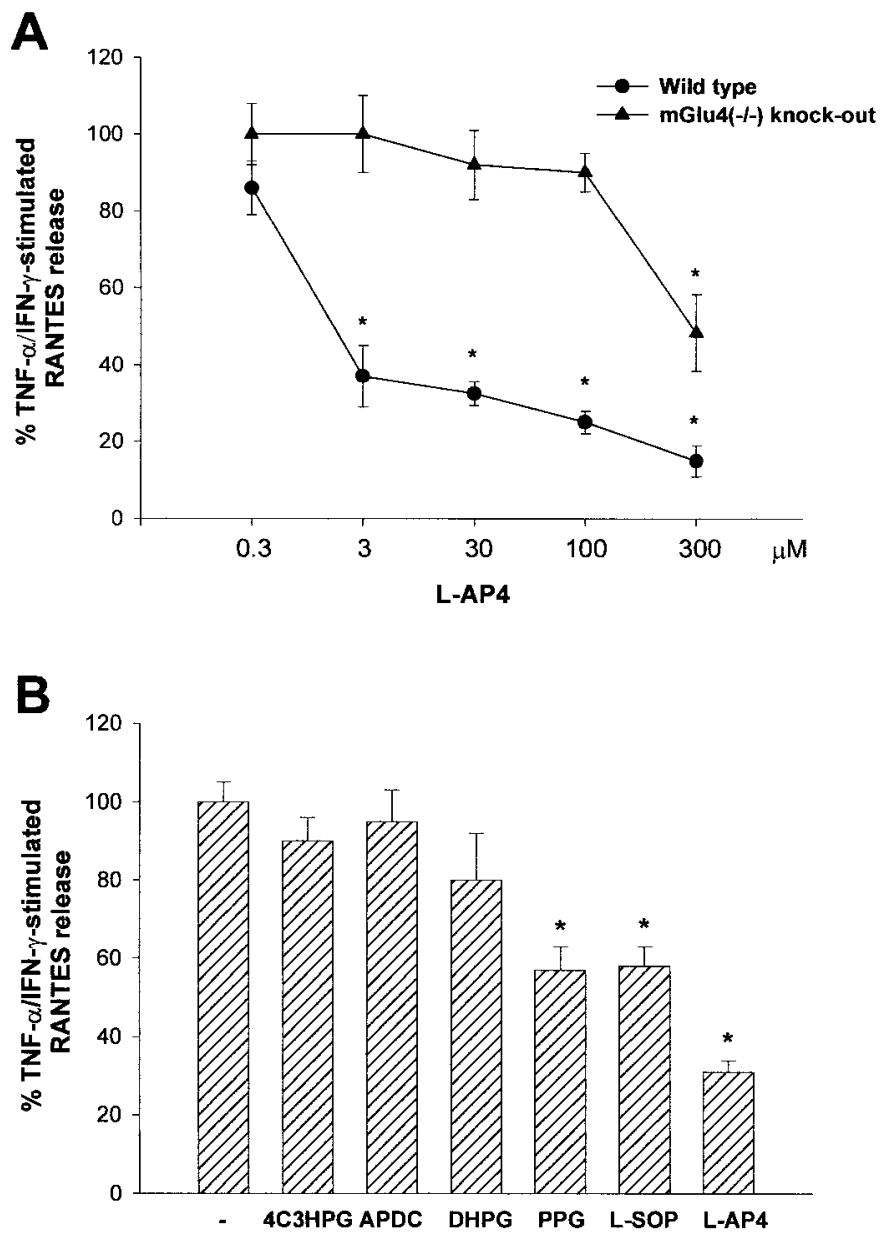

Figure 1. Extracellular RANTES levels in mouse cultured astrocytes exposed to TNF- $\alpha$ and IFN- $\gamma$ in the absence or presence of mGlu receptor ligands. $A$, Concentration-dependent effect of L-AP-4 on the increase in extracellular RANTES induced by TNF- $\alpha$ and IFN- $\gamma$ in cultured cortical astrocytes prepared from wild-type or knock-out mouse cortical astrocytes. Addition of TNF- $\alpha$ and IFN- $\gamma$ increased extracellular RANTES levels from $0.15 \pm 0.02$ to $6.7 \pm 0.81 \mathrm{ng} / \mathrm{mg}$ protein in wild-type cultures and from $0.08 \pm 0.04$ to $5.9 \pm 0.63 \mathrm{ng} / \mathrm{mg}$ protein in mGlu4(-/-) cultures. Values were calculated as a percentage of cytokine-stimulated RANTES release and represent the means \pm SEM of six determinations. ${ }^{*} p<0.05$ (one-way ANOVA + Fisher's PLSD) as compared with TNF- $\alpha$ and IFN- $\gamma$ alone. $B$, Effect of different mGlu receptor ligands on the increase in extracellular RANTES induced by TNF- $\alpha$ and IFN- $\gamma$ in mouse cultured astrocytes. Values were calculated from 6-12 determinations from at least three individual multiplates. All mGlu receptor ligands were added at concentrations of $100 \mu \mathrm{M}$ with the exception of L-SOP $(300 \mu \mathrm{M}) .{ }^{*} p<0.05$ (one-way ANOVA and Fisher's PLSD) as compared with values obtained in the absence of mGlu receptor ligands $(-)$.

washed. Adherent cells were then removed from the plate using trypsin. This enriched monocyte fraction was $85-90 \% \mathrm{CD} 4^{+}$by flow cytometric analysis. $\mathrm{CD} 8^{+}$cells were obtained from whole PBMCs by negative selection. Briefly, cells were incubated with an antibody cocktail containing microbeads against CD4, 11b, 14, 16, 19, 36, 56, and IgE (Miltenyi Biotec) for $30 \mathrm{~min}$ at $4^{\circ} \mathrm{C}$. Cells were washed and passed over a permanent magnet. The negative fraction was $>95 \% \mathrm{CD} 8^{+}$as determined by flow cytometric analysis. Cells were preincubated with appropriate concentration of L-AP-4 for $30 \mathrm{~min}$ at $37^{\circ} \mathrm{C}$ and seeded at $2 \times 10^{5}$ cells per well in 96-well plates. Phorbol-12-myristate-13-acetate (PMA) was added, and cultures were incubated for $48 \mathrm{hr}$ at $37^{\circ} \mathrm{C}$. Supernatants were collected and stored at $-80^{\circ} \mathrm{C}$. For the determination of extracellular RANTES, human anti-RANTES antibody (Genzyme Techne) was coated on a 96 -well plate $(10 \mu \mathrm{g} / \mathrm{ml})$ at $4^{\circ} \mathrm{C}$ for $18 \mathrm{hr}$. Plate was washed
Table 1. MSOP antagonizes the reduction in extracellular RANTES levels induced by L-AP4

$\mathrm{ng} / \mathrm{mg}$ prot

TNF- $\alpha+$ IFN- $\gamma$

+ L-AP4, $30 \mu \mathrm{M}$

$7.14 \pm 0.66$

+ MSOP, $100 \mu \mathrm{M}$

$3.56 \pm 0.12^{*}$

+ L-AP4 + MSOP

$8.53 \pm 0.38$

Values are means \pm SEM of four individual determinations.

${ }^{*} p<0.05$ (one-way ANOVA + Fisher's PLSD) compared with all other groups.

three times with PBS. Nonspecific sites were blocked by an incubation with PBS supplemented with 5\% BSA. After washing plate with PBS + $0.05 \%$ Tween $20,50 \mu \mathrm{l} /$ well supernatant was added and incubated at room temperature for $2 \mathrm{hr}$. A Europium-labeled anti-R ANTES antibody was added (a kind gift from H. Inbe, Department of Biological Chemistry, Yamaguchi University, Yamaguchi, Japan) and incubated for a further $2 \mathrm{hr}$ at room temperature. Plate was washed using PBS $+0.05 \%$ Tween 20 at $300 \mu \mathrm{l} /$ well. Enhancement solution (LKB-Wallac, Gaithersburg, MD) was added at $100 \mu \mathrm{l} /$ well and incubated at room temperature for $10 \mathrm{~min}$. The plate was then measured for Europium counts using a Wallac Arvo SX Multi-Label counter (Wallac).

\section{RESULTS}

\section{Activation of group III $\mathrm{mGlu}$ receptors reduces the production of RANTES in primary cultures of glial cells}

We used confluent cultures of glial cells, which were primarily constituted of flat and polygonal type-1 astrocytes. Cultures were virtually devoid of microglial cells (only 6-10 cells per well stained with the lectin, Banderiera simplicifolia I). A $15 \mathrm{hr}$ exposure of mouse cultured glial cells to $0.1 \mathrm{ng} / \mathrm{ml}$ of TNF- $\alpha$ plus 10 $\mathrm{U} / \mathrm{ml}$ of IFN- $\gamma$ led to a substantial increase in the amount of RANTES released into the medium. L-AP-4 applied in combination with TNF- $\alpha$ and IFN- $\gamma$ reduced extracellular RANTES levels in a concentration-dependent manner, with an apparent $\mathrm{EC}_{50}$ value of $6 \mu \mathrm{M}$ (Fig. $1 A$ ). Among other mGlu receptor ligands, L-SOP $(300 \mu \mathrm{M})$ and PPG $(100 \mu \mathrm{M})$ were also able to reduce extracellular RANTES. 4C3HPG, $2 R, 4 R$-APDC, and DHPG (all at $100 \mu \mathrm{M}$ ) had negligible, if any, effect on the cytokine-stimulated increase in extracellular RANTES (Fig. $1 B)$. The group III mGlu receptor antagonist MSOP $(100 \mu \mathrm{M})$ produced a slight increase in extracellular RANTES on it own, but markedly reduced the inhibitory action of L-AP-4 $(30 \mu \mathrm{M})$ (Table 1). None of the $\mathrm{mGlu}$ receptor ligands induced changes in extracellular RANTES in the absence of TNF- $\alpha$ and IFN- $\gamma$ (data not shown). We also assessed intracellular RANTES mRNA and protein levels in mouse cultured glial cells. Northern blot analysis showed that RANTES mRNA levels were nearly undetectable in untreated cultures but increased substantially after a $15 \mathrm{hr}$ treatment with TNF- $\alpha$ and IFN- $\gamma$. This increase was markedly reduced by L-AP-4 $(100 \mu \mathrm{M})$ or PPG $(100 \mu \mathrm{M})$, but was minimally affected by $2 R, 4 R$-APDC $(100 \mu \mathrm{M})$ or DHPG $(100 \mu \mathrm{M})$ (Fig. $2 A, B)$. Similarly, L-AP-4 reduced the cytokine-induced increase in RANTES protein levels, and its action was attenuated in cultures pretreated with pertussis toxin (PTX) (Fig. 3).

Finally, we measured the ability of L-AP-4 to reduce cytokinestimulated RANTES production in cultured glial cells prepared from knock-out mice lacking mGlu4 receptors. In mGlu4(-/-) cultures a 15 -hr treatment with TNF- $\alpha+$ IFN- $\gamma$ increases the extracellular levels of RANTES to the same extent as in cultures from wild-type mice. L-AP-4 could still reduce cytokinestimulated RANTES release in mGlu4(-/-) cultures, but only at concentrations of $300 \mu \mathrm{M}$ (Fig. 1A). 
A

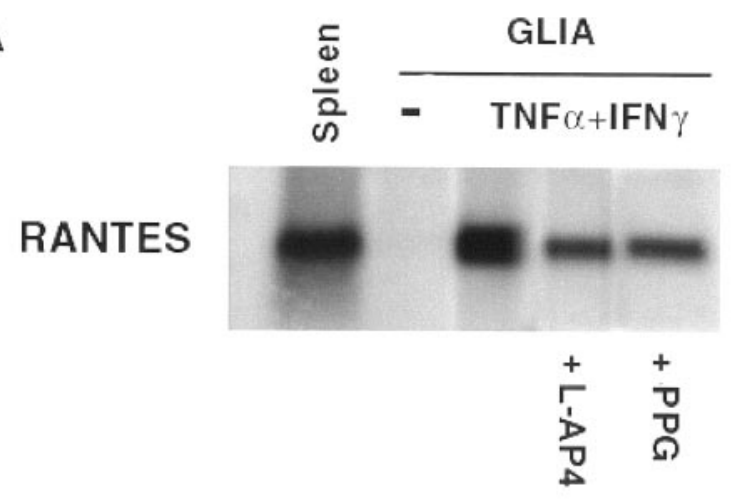

B

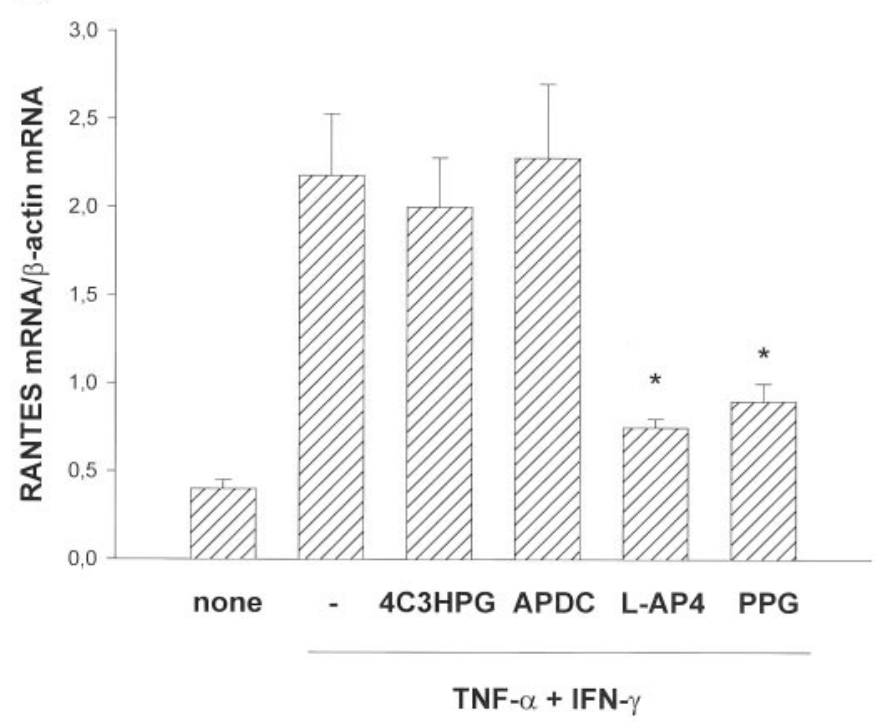

Figure 2. RANTES mRNA levels in mouse cultured astrocytes incubated for $15 \mathrm{hr}$ with TNF- $\alpha$ and IFN- $\gamma$ in the absence or presence of different mGlu receptor agonists. $A$, Representative Northern Blot of RANTES mRNA in mouse cultures of astrocytes. In the first lane, the spleen is shown as a positive control. Note that RANTES mRNA levels were nearly undetectable in untreated cultures $(-)$, but increased substantially after a $15 \mathrm{hr}$ treatment with TNF- $\alpha$ and IFN- $\gamma$. This increase was markedly reduced by L-AP-4 or PPG (both at $100 \mu \mathrm{M}$ ). B, Densitometric analysis of RANTES mRNA levels in cultured astrocytes incubated for $15 \mathrm{hr}$ with TNF- $\alpha$ and IFN- $\gamma$ in the absence or presence of 4C3HPG, $2 R, 4 R$-APDC ( $A P D C$ ), L-AP-4, or PPG (all at $100 \mu \mathrm{M}$ ). Values were normalized by the amount of $\beta$-actin mRNA and represent the means \pm SEM of three determinations. $* p<0.05$ (one-way ANOVA plus Fisher's PLSD) versus cultures treated with TNF- $\alpha$ and IFN- $\gamma$ alone (-).

\section{Detection of mGlu4 receptors in cultured glial cells}

In immunoblots, mGlu4 antibodies labeled a major band at $\sim 100$ $\mathrm{kDa}$, which corresponds to the receptor monomer. This band was detected in cultured glial cells from wild-type mice or Lewis rats, but not in cultures from mGlu4(-/-) mice (Fig. $4 A$ ). The presence of mGlu4 receptors in cultured glial cells was confirmed by RT-PCR analysis (Fig. 4B).

\section{Effect of L-AP-4 on the development of EAE in Lewis rats}

To assess whether the modulation of RANTES formation in glial cells has any functional relevance, we examined the effect of systemically injected L-AP-4 in the EAE model of neuroinflam-

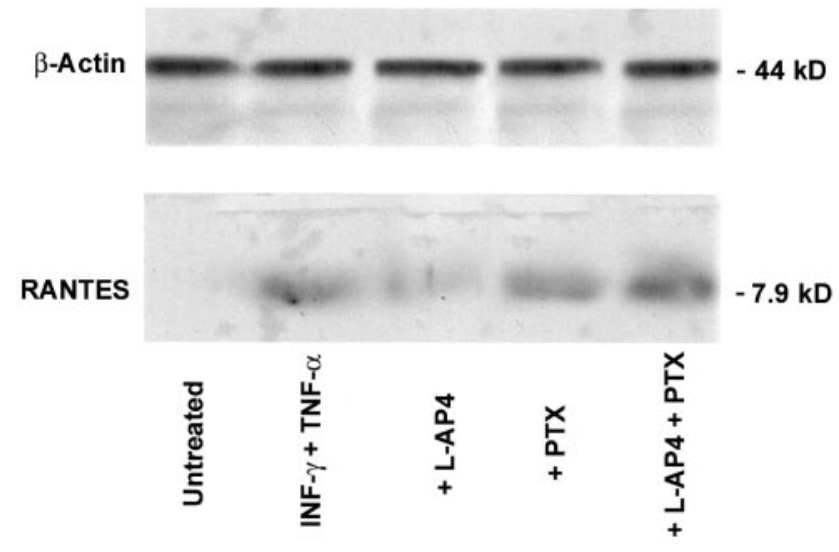

Figure 3. Western blot analysis of RANTES in mouse cultured astrocytes incubated for $15 \mathrm{hr}$ with TNF- $\alpha$ and IFN- $\gamma$ in the absence or presence of L-AP-4 $(100 \mu \mathrm{M})$ and/or PTX $(0.5 \mu \mathrm{g} / \mathrm{ml}$, preincubated for 16 $\mathrm{hr}$ before the incubation with the cytokines). Note that PTX abolished the reduction in RANTES levels induced by L-AP-4.
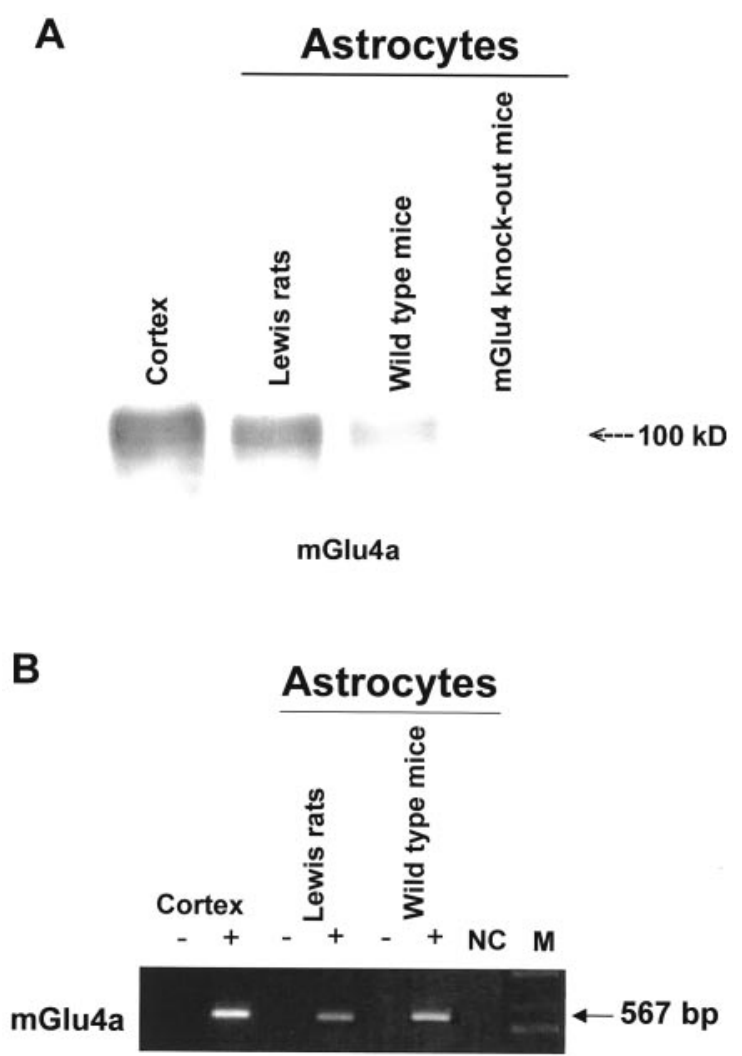

Figure 4. Expression of mGlu4a receptor in cultured astrocytes. A, Western blot analysis of mGlu4a receptor in cultured astrocytes from wild-type mice, mGlu4(-/-) mice, or Lewis rats. Expression in the cerebral cortex of wild-type mice is shown as a positive control. The antibody recognized a specific band corresponding to the monomeric form of receptor at $100 \mathrm{kDa}$ (arrow). B, RT-PCR analysis of mGlu4a receptor mRNA in cultured astrocytes from wild-type mice or Lewis rats. $(-)$ and $(+)$ refer to the absence or presence of reverse transcriptase. Mouse cerebral cortex is shown as reference tissue. NC represents a negative control in which $\mathrm{dH}_{2} \mathrm{O}$ has been loaded instead of cDNA. Size markers $(M)$ are on the last lane on the right. 

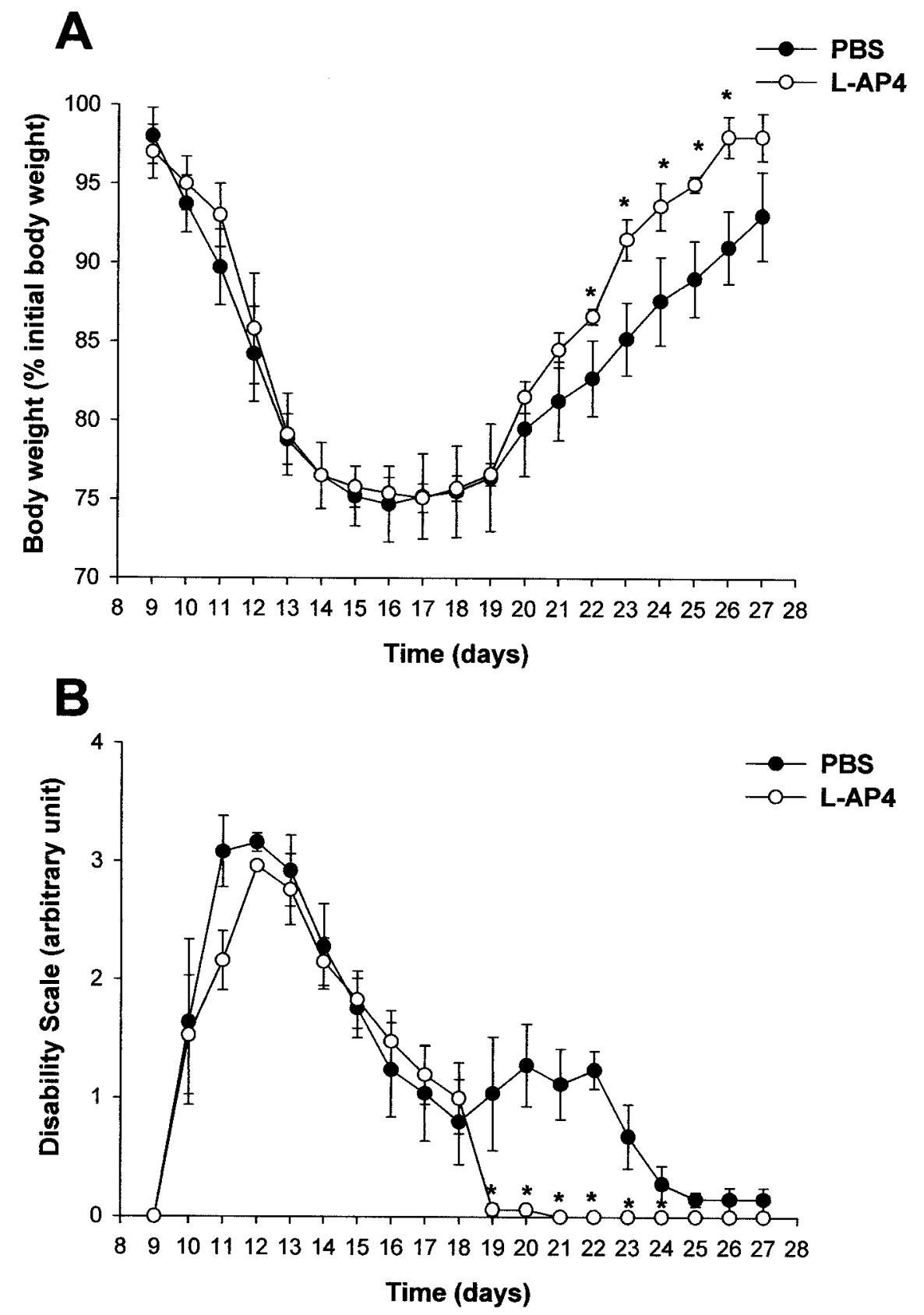

Figure 5. Effect of L-AP-4 on the development of EAE in Lewis rats. $A$, Temporal profile of body weight in animals immunized with MBP implanted with an osmotic minipump, which released $250 \mathrm{nl} / \mathrm{d}$ of PBS or a PBS solution containing $250 \mathrm{~mm}$ of L-AP-4. $B$, Temporal profile of the disability score of EAE. Note that rats treated with L-AP-4 showed a faster recovery rate from EAE than control rats. Values express the means \pm SEM of 10 animals per group. ${ }^{*} p<0.05$ (one-way ANOVA and Fisher's PLSD) versus PBS-treated animals. mation in Lewis rats. Immunization of Lewis rats with guinea pig MBP induced the classical symptoms of EAE after a latency of $10 \mathrm{~d}$, as assessed by the disability scale and by the loss of body weight. In standard experiments, the course of EAE was biphasic, showing a peak at 11-13 d after immunization, followed by a drop in the score during days $14-18$ and by a plateau phase with scores of 1-1.5 lasting until day 23. No relapses were observed after full recovery of EAE. Figure 5 shows the temporal profile of EAE in control rats and in rats implanted with a subcutaneous osmotic minipump releasing $250 \mathrm{nl} / \mathrm{d}$ of a PBS solution containing $250 \mathrm{~mm}$ of L-AP-4. The pump was implanted $2 \mathrm{~d}$ before immunization. Detectable amounts of L-AP-4 (105 $\pm 37 \mathrm{nM} ; n=3)$ were detected in the striatal dialysate of freely moving rats, suggesting that some amounts of subcutaneously infused L-AP-4 can penetrate the brain. No gross abnormalities in motor behavior were observed in nonimmunized rats treated with L-AP-4 or in immu- nized rats infused with L-AP-4 before the clinical onset of EAE, as detected by measuring locomotor activity in an open field apparatus (data not shown). In rats treated with L-AP-4 there was no difference in the time at onset and in the peak of the disability score of EAE, as compared with control rats implanted with a minipump containing PBS alone, although L-AP-4-treated rats reached the peak of the disability score $1 \mathrm{~d}$ later than control rats (i.e., 12 instead of $11 \mathrm{~d}$ after immunization). However, rats treated with L-AP-4 showed a faster recovery rate from EAE, as indicated by the absence of the plateau phase, and showed a full recovery after $19 \mathrm{~d}$ (vs 24 or $25 \mathrm{~d}$ in control rats) (Fig. 5A,B). Independent groups of animals were used for histological examination. Neuroinflammation was assessed by immunohistochemical analysis of $\mathrm{MHC}-\mathrm{II}^{+}$and $\mathrm{CD}^{+}{ }^{+}$cells in the spinal cord (MHC-II $^{+}$cells in the spinal cord of immunized animals are shown in the lower panel of Fig. $6 A$ ). We adopted a semiquanti- 
A

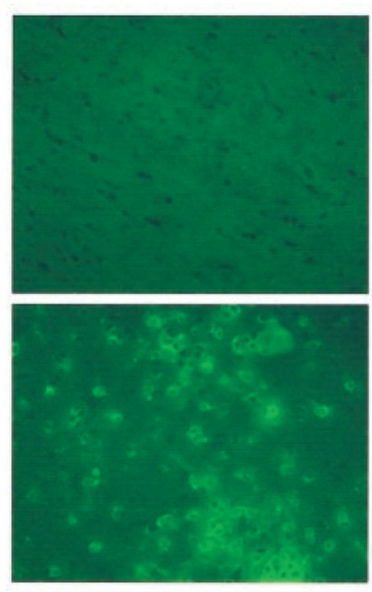

C

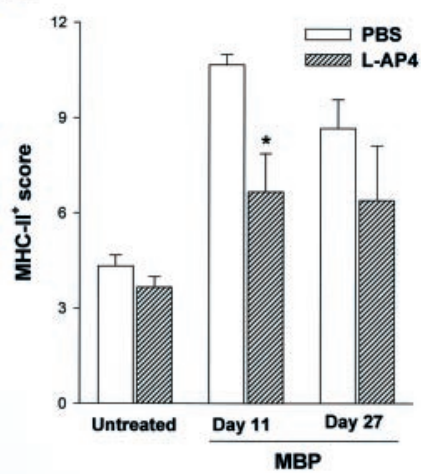

B

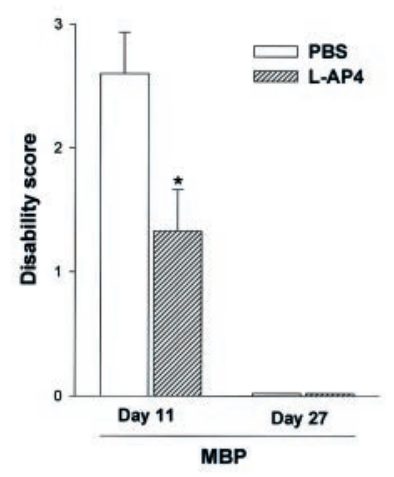

D

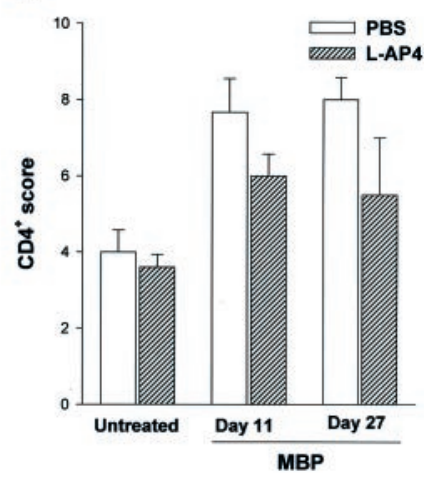

Figure 6. Immunohistochemistry of ${\mathrm{MHC}-\mathrm{II}^{+}}^{+}$and $\mathrm{CD} 4{ }^{+}$cells in the spinal cord of nonimmunized or immunized Lewis rats subcutaneously infused with L-AP-4. An example of MHC-II immunostaining in the spinal cord of nonimmunized (top panel) and immunized (bottom panel) rats is shown in $A$. The disability score of immunized animals killed at 11 or $27 \mathrm{~d}$ after MBP injection and used for immunohistochemical analysis is shown in $B$ (mean + SEM of three to five determinations; * $p<0.05$; Student's $t$ test vs the respective group of rats subcutaneously inf used with saline). Quantification of MHC-II and CD4 immunostaining in nonimmunized (untreated) or immunized $(M B P)$ rats subcutaneously infused with PBS or L-AP-4 is shown in $C$ and $D$, respectively. Immunized rats were examined at day 11 or 27 after injection of MBP. Untreated rats were examined $13 \mathrm{~d}$ after implantation of osmotic minipumps releasing either saline or L-AP-4. Values are means + SEM of three to five determinations; * $p<0.05$ (one-way ANOVA and Fisher's PLSD, as compared with the respective group implanted with minipumps releasing saline).

tative scale with scores from 0 to 4 referred to the intensity of staining, number of immunopositive cells within identified clusters of cells, and distribution of clusters of immunopositive cells (maximal score $=12$; modified from Di Marco et al., 2001). Animals were examined at day 11 or 27 after immunization. A substantial increase in the neuroinflammation score for both MHC-II and CD4 was observed in the spinal cord of immunized animals after $11 \mathrm{~d}$, i.e., at the time of the peak of motor symptoms. The score was only slightly reduced at $27 \mathrm{~d}$, when animals were apparently asymptomatic (Fig. $6 B-D$ ). Immunized rats that received L-AP-4 subcutaneously had a lower disability score at day 11 (Fig. 6B) and a lower number of $\mathrm{MCH}^{-\mathrm{II}^{+}}$cells in the spinal cord (Fig. 6C). The MCH-II score showed a trend to a reduction also at $27 \mathrm{~d}$ in immunized animals treated with L-AP-4 (Fig. 6C). This trend with L-AP-4 was also observed by scoring
CD4 immunoreactivity at 11 and $27 \mathrm{~d}$ after immunization (Fig. $6 D)$. In other animals we measured RANTES mRNA levels in the cerebellum and spinal cord at the time of the peak of the disability score. Northern blot analysis showed that treatment with L-AP-4 reduced RANTES mRNA levels in the cerebellum and spinal cord of EAE rats (Fig. 7). Because systemically injected L-AP-4 gave only a partial protection against EAE, we decided to examine whether the drug had any effect on the production of RANTES by other cells that contribute to the pathophysiology of EAE, such as leukocytes. Experiments were performed on human purified protein derivative-derived Th1 clones, $\mathrm{CD}^{+}$leukocytes, and monocytes, in which the production and release of RANTES was stimulated by PMA (0.1-10 $\mathrm{ng} / \mathrm{ml})$. Addition of L-AP-4 (0.1-1000 $\mu \mathrm{M})$ had no effect on extracellular RANTES in Th1 clones and showed a trend to reduction of extracellular RANTES in $\mathrm{CD}^{+}$cells and monocytes. However, this trend was observed only with high concentrations of L-AP-4 (100 or $1000 \mu \mathrm{M})$ and was not statistically significant (Fig. $8 A-C$ ).

\section{DISCUSSION}

RANTES is a $\beta$ chemokine that is gaining more and more interest for its role in neuroinflammation. Similar to monocyte chemoattractant protein-1 (MCP-1) and interferon- $\gamma$-inducible protein-10 (IP-10), RANTES is chemoattractant for monocytes, and contributes to the pathophysiology of immune disorders, including MS (Ransohoff, 1999). RANTES can also attract memory $\mathrm{T}$ and NK cells, which are involved in MS, and act as an antigen-independent activator of $\mathrm{T}$ cells in vitro (Schall et al., 1990; Bacon et al., 1995; Taub et al., 1995). In EAE, RANTES amplifies the inflammatory process, and its expression correlates with the intensity of neuroinflammation (Glabinski et al., 1998; Ransohoff, 1999). In addition, RANTES has been associated with the early formation of plaques (Simpson et al., 1998), and the RANTES receptor CCR5 has been found in lymphocytes and phagocytes of actively demyelinating lesions in MS (Bacon and Oppenheim, 1998; Sorensen et al., 1999). Interestingly, the production of RANTES by peripheral mononuclear cells is reduced after treating MS patients with IFN- $\beta$-1b (Iarlori et al., 2000; Zang et al., 2001), suggesting that the modulation of RANTES production may be a valuable target in the pharmacological treatment of MS patients. We examined the possibility that the production of RANTES could be modulated by the activation of glial membrane receptors. In particular, we focused on mGlu receptors, which are G-protein-coupled receptors activated by glutamate and other excitatory amino acids. mGlu receptors form a family of eight subtypes, which are subdivided into three groups on the basis of their sequence homology, pharmacological profile, and transduction pathways. Group I includes mGlu1 and -5 receptors, which are coupled to inositol phospholipid hydrolysis and activated by DHPG. Group II includes mGlu2 and -3 receptors, which are coupled to $\mathrm{G}_{\mathrm{i}}$-proteins and activated by $2 R, 4 R$-APDC. $4 \mathrm{C} 3 \mathrm{HPG}$ behaves as a mixed $\mathrm{mGlu} 2 / 3$ agonist/mGlu1 antagonist. Group III includes mGlu4, $-6,-7$, and -8 receptors, which are also coupled to $\mathrm{G}_{\mathrm{i}}$-proteins and selectively activated by L-AP-4, PPG, and L-SOP (Pin and Duvoisin, 1995; Schoepp et al., 1999). Whereas mGlu3 and -5 receptors are expressed by astrocytes (Miller et al., 1995; Petralia et al., 1996; Ciccarelli et al., 1999), evidence for the expression of group III mGlu receptors in glial cells is still lacking. Hence, we used primary cultures of glial cells, expecting that mGlu3 or -5 receptor agonists could modulate the production of RANTES. Unexpectedly, however, only group III 


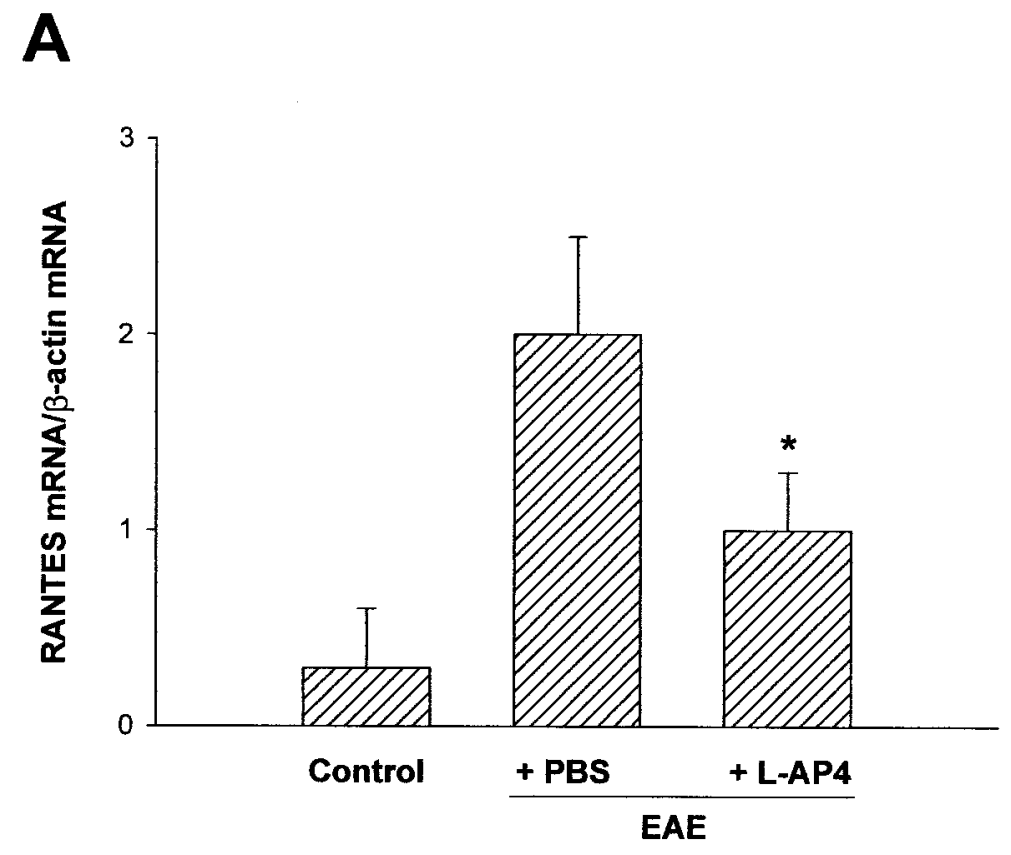

B

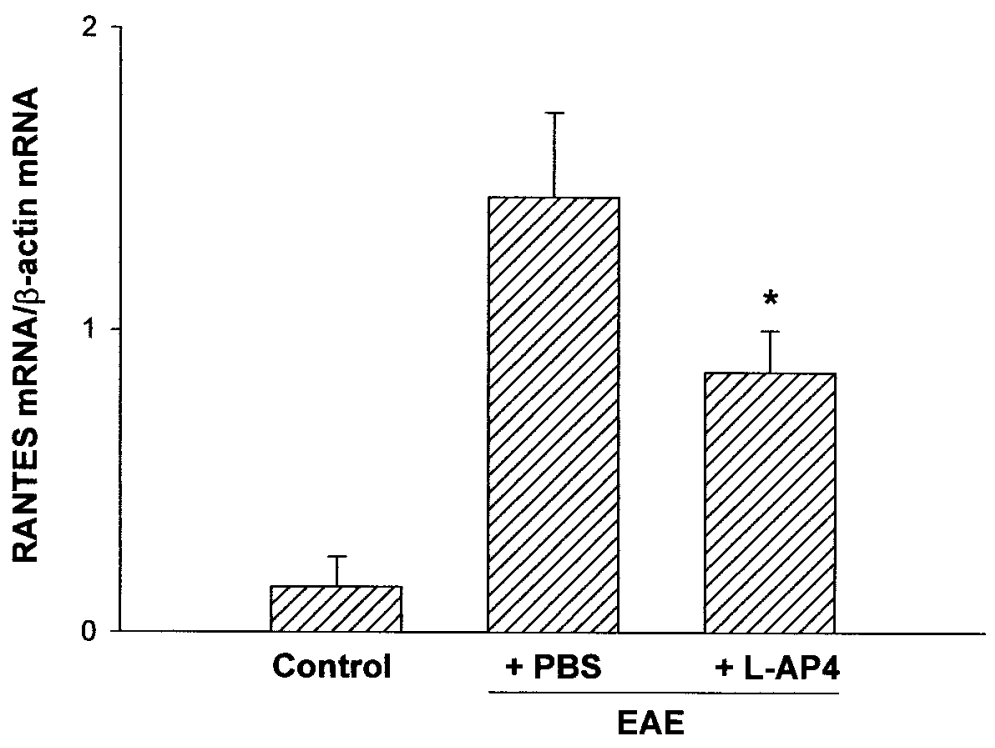

Figure 7. Expression of RANTES mRNA levels in the cerebellum and spinal cord of EAE rats subcutaneously infused with PBS or L-AP-4. $A$, Densitometric analysis of RANTES mRNA levels in the cerebellum and spinal cord is shown in $A$, and $B$, respectively. Values were normalized by the amount of $\beta$-actin mRNA and express the means \pm SEM of three determinations. $* p<0.05$ (one-way ANOVA and Fisher's PLSD) versus treated animals. Subcutaneous infusion of L-AP-4 in nonimmunized rats did not induce changes in RANTES mRNA levels in the cerebellum and spinal cord $(93+7.8 \%$ of controls in the cerebellum and $137+28 \%$ of controls in the spinal cord, $13 \mathrm{~d}$ after implantations of osmotic minipumps; $n=4$ ).
mGlu receptor agonists (i.e., L-AP-4, PPG, or L-SOP) reduced RANTES levels in cultures stimulated with TNF- $\alpha$ and IFN- $\gamma$. L-AP-4, the prototypic agonist of group III mGlu receptors, produced the more substantial and reproducible effect on RANTES levels, and its action was sensitive to the group III mGlu receptor antagonist MSOP (Schoepp et al., 1999) and to PTX, which inhibits the activity of $\mathrm{G}_{\mathrm{i}}$-proteins. The reduction of RANTES mRNA levels by L-AP-4 or PPG suggested that these drugs act at transcriptional level or decrease the stability of RANTES mRNA. The calculated $\mathrm{EC}_{50}$ value for L-AP-4 is consistent with the activation of mGlu4 or -8 rather than mGlu 7 receptors, which can be recruited only by concentrations of L-AP-4 $>100 \mu \mathrm{M}$ (Schoepp et al., 1999). At least mGlu4 receptors appeared to be expressed by cultured glial cells. It is unlikely that expression of
mGlu4 receptors derived from contaminating microglia, because only 6-10 microglial cells per well were detected with a method that was highly efficacious in detecting microglia in the inflammatory infiltrate of EAE rats (data not shown). In cultures from mGlu4 knock-out mice, only concentrations of L-AP-4 $>100 \mu \mathrm{M}$ were still able to reduce the production of RANTES. This indicates that glial mGlu4 receptors primarily contribute to the regulation of RANTES formation in astrocytes. Whether the effect produced by $300 \mu \mathrm{M}$ L-AP-4 reflects the recruitment of $\mathrm{mGlu} 7$ receptors or rather represents a nonspecific effect of the drug remains to be determined. Moving from the in vitro data, we decided to examine the effect of L-AP-4 on EAE in Lewis rats. Because EAE develops gradually after a latency period of $\sim 10 \mathrm{~d}$, we continuously infused L-AP-4 by means of a subcutaneous 
A

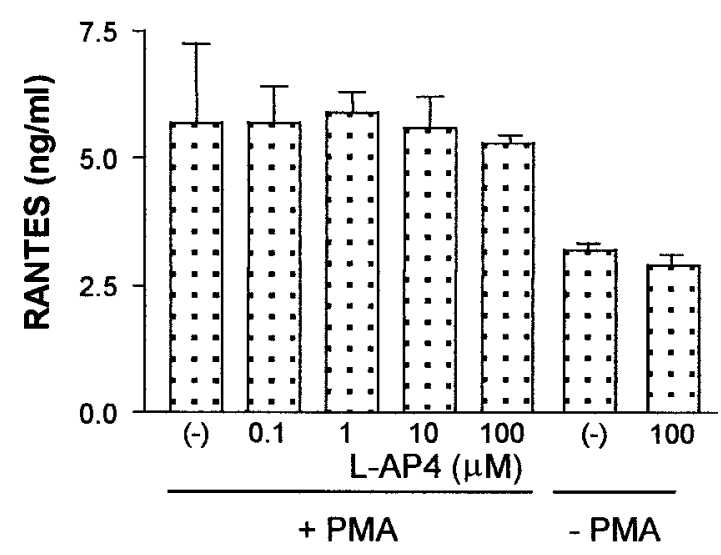

B

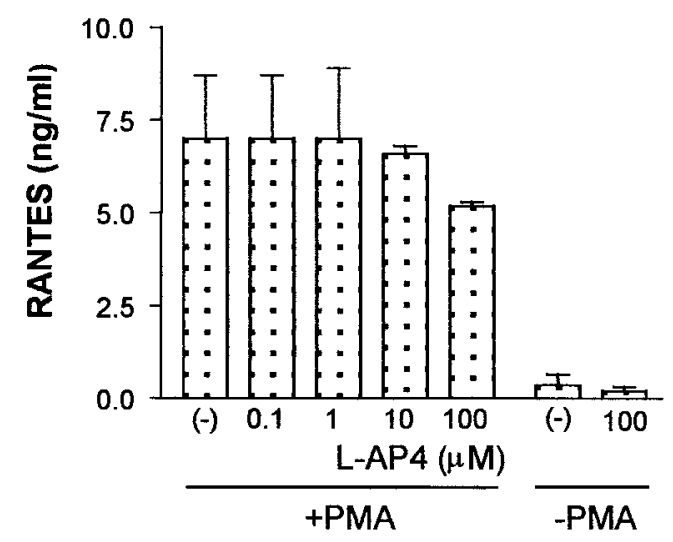

C

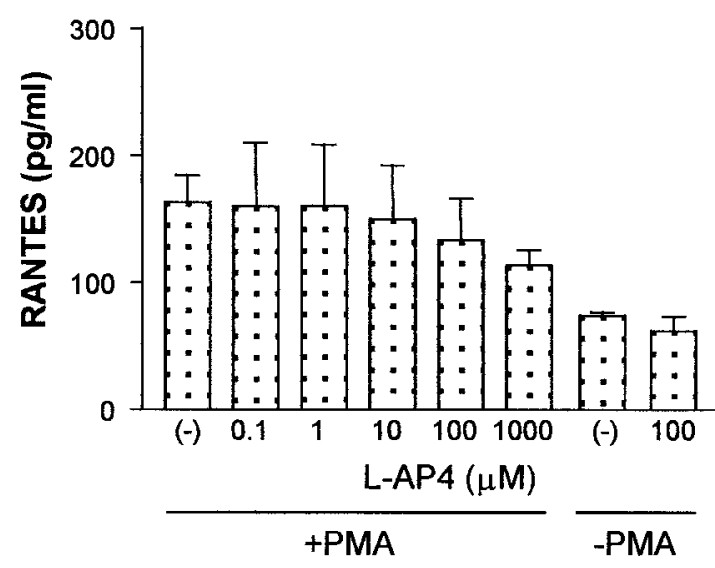

Figure 8. Effect of L-AP-4 on RANTES release in Th1 clones $(A)$, $\mathrm{CD}^{+}$leukocytes $(B)$, or monocytes $(C)$, stimulated for $48 \mathrm{hr}$ with 0.1 $\mathrm{ng} / \mathrm{ml}$ of PMA. Values are means $\pm \mathrm{SEM}$.

osmotic minipump. We used this strategy because the increased permeability of the blood-brain barrier during the development of EAE (Perry et al., 1997) could allow a sufficient penetration of L-AP-4 into the brain. To assess whether this assumption was correct, we measured extracellular brain levels of L-AP-4 by in vivo microdialysis. The amount of L-AP-4 found in the dialysate $(\sim 100 \mathrm{nM})$ suggests that concentrations of L-AP-4 in the range of $0.1-1 \mu \mathrm{M}$ should be present in the extracellular space. These concentrations may be sufficient to activate mGlu4 receptors (Schoepp et al., 1999). Infusion of L-AP-4 neither delayed the time at onset nor reduced the severity of EAE symptoms, although treated animals reached the peak of the disability score $1 \mathrm{~d}$ later. Interestingly, however, treatment with L-AP-4 increased the rate of recovery from EAE. The second phase of motor disability, which was present in animals infused with PBS from day 18 to day 23 after immunization, was not observed in animals that received L-AP-4. Because EAE in Lewis rats represents a model of neuroinflammation, but not of demyelination, we suggest that L-AP-4 infusion reduces the inflammatory infiltrate in the brain parenchyma to an extent that does not prevent the development of EAE but allows a faster recovery from the disease (Miyagishi et al., 1997). Accordingly, immunized animals treated with L-AP-4 showed a reduced immunostaining for $\mathrm{MHC}$ class II in the spinal cord and a trend to a reduction in CD4 immunostaining in the spinal cord at day 11 after immunization. The partial reduction of RANTES mRNA levels produced by L-AP-4 infusion in the cerebellum and spinal cord of EAE rats might account for the $1 \mathrm{~d}$ delay in reaching the peak of the disability score, the reduced extent of neuroinflammation, and the lack of the delayed plateau phase of the disability score. The possibility that the delayed plateau phase is sustained by the release of RANTES from glial cells is interesting and deserves further investigation. The lack of a more robust effect of L-AP-4 on EAE may reflect the inability of the drug to reduce the production of RANTES from other cells that directly contribute to the inflammatory infiltrate, such as leukocytes. Accordingly, L-AP-4 did not reduce the release of RANTES stimulated by phorbol esters in lymphocytes or monocytes, although a trend to a reduction with high concentrations of L-AP-4 was seen in CD8 ${ }^{+}$ lymphocytes and in monocytes.

In conclusion, present results offer the first demonstration that group III mGlu receptors are expressed and functional in glial cells. The unexpected finding that activation of these receptors reduces the production of RANTES in astrocytes suggests that brain-permeable agonists may be useful in the experimental treatment of neuroinflammatory disorders of the CNS. The potential usefulness of group III mGlu receptor agonists in human pathology awaits the demonstration that these drugs show good safety and tolerability when systemically injected.

\section{REFERENCES}

Bacon KB, Oppenheim JJ (1998) Chemokines in disease models and pathogenesis. Cytokine Growth Factor Rev 9:167-173.

Bacon KB, Premack BA, Gardner P, Schall TJ (1995) Activation of dual $\mathrm{T}$ cell signalling pathways by the chemokine RANTES. Science 269:1727-1730.

Barnes DA, Huston M, Holmes R, Benveniste EN, Yong VW, Scholz P, Perez HD (1996) Induction of RANTES expression by astrocytes and astrocytoma cell lines. J Neuroimmunol 71:207-214.

Bazan JF, Bacon KB, Hardiman G, Wang W, Soo K, Rossi D, Greaves DR, Zlotnik A, Shall TJ (1997) A new class of membrane-bound chemokine with $\mathrm{CX}_{3} \mathrm{C}$ motif. Nature 385:640-644.

Bradley SR, Levey AI, Hersch SM, Conn PJ (1996) Immunocytochemical localization of group III metabotropic glutamate receptors in the hippocampus with subtype-specific antibodies. J Neurosci 16:20442056.

Bradley SR, Standaert DG, Rhodes KJ, Rees HD, Testa CM, Levey AI, Conn PJ (1999) Immunoistochemical localization of subtype 4a metabotropic glutamate receptors in the rat and mouse ganglia. J Comp Neurol 407:33-46.

Ciccarelli R, Di Iorio P, Bruno V, Battaglia G, D'alimonte G, D'Onofrio M, Nicoletti F, Caciagli F (1999) Activation of A1 adenosine or mGlu3 metabotropic glutamate receptors enhances the release of nerve growth factor and S-100 $\beta$ protein from cultured astrocytes. Glia 27:275-281.

Ciccarelli R, Di Iorio P, D'Alimonte I, Giuliani P, Florio T, Caciagli F Middlemiss PJ, Rathbone MP (2000) Cultured astrocyte proliferation induced by extracellular guanosine involves endogenous adenosine and is raised by the co-presence of microglia. Glia 29:202-211. 
Chomczynski P, Sacchi N (1987) Single-step method of RNA isolation by acid guanidium thiocyanate-phenol-chloroform extraction. Anal Biochem 162:156-159.

Di Marco R, Khademi M, Wallstrom E, Iacobaeus E, Salvaggio A, Caracappa S, Papoian R, Nicoletti F, Olsson T (2001) Curative effects of recombinant human Interleukin-6 in DA rats with protracted relapsing experimental allergic encephalomyelitis. J Neuroimmunol 116:168-177.

Glabinski AR, Tuohy VK, Ransohoff RM (1998) Expression of chemokines RANTES, MIP-1 alpha and GRO-alpha correlates with inflammation in acute experimental autoimmune encephalomyelitis. Neuroimmunomodulation 5:166-171.

Godiska R, Chantry D, Dietsch GN, Gray PW (1995) Chemokine expression in murine experimental allergic encephalomyelitis. J Neuroimmunol 58:167-176.

Iarlori C, Reale M, Lugaresi A, De Luca G, Bonanni L, Di Iorio A, Feliciani C, Conti P, Gambi D (2000) RANTES production and expression is reduced in relapsing-remitting multiple sclerosis patients treated with interferon- $\beta-1 \mathrm{~b}$. J Neuroimmunol 107:100-107.

Mennicken F, Maki R, de Souza EB, Quirion R (1999) Chemokines and chemokine receptors in the CNS: a possible role in neuroinflammation and patterning. Trends Pharmacol Sci 20:73-77.

Miller S, Romano C, Cotman CW (1995) Growth factor upregulation of a phosphoinositide-coupled metabotropic glutamate receptor in cortical astrocytes. J Neurosci 15:6103-6109.

Miyagishi R, Kikuchi S, Takayama C, Inoue Y, Tashiro K (1997) Identification of cell types producing RANTES, MIP- $1 \alpha$ and MIP- $1 \beta$ in rat experimental autoimmune encephalomyelitis by in situ hybridization. J Neuroimmunol 77:17-26.

Pan Y, Lloyd C, Zhou H, Dolich S, Deeds J, Gonzalo JA, Vath J, Gosselin M, Ma J, Dussault B, Woolf E, Alperin J, Culpepper J, Gultierrez-Ramos JC, Gearing D (1997) Neurotactin, a membraneanchored chemokine upregulated in brain inflammation. Nature 387: 611-617.

Pellegrino JL, Pellegrino SA, Cushman JA (1992) A stereotaxic atlas of the rat brain. New York: Plenum.

Perry VH, Anthony DC, Bolton SJ, Brown HC (1997) The blood-brain barrier and the inflammatory response. Mol Med Today 3:335-341.
Petralia RS, Wang W-X, Niedzielski AS, Wenthold RJ (1996) The metabotropic glutamate receptors mGluR2 and mGluR3 show unique postsynaptic, presynaptic and glial localization. Neuroscience 71:949-976.

Pin JP, Duvoisin R (1995) The metabotropic glutamate receptors: structure and functions. Neuropharmacology 34:1-26.

Ransohoff RM (1999) Mechanism of inflammation in MS tissue: adhesion molecules and chemokines. J Neuroimmunol 98:57-68.

Ransohoff RM, Bacon KB (2000) Chemokine receptor antagonism as a new therapy for multiple sclerosis. Exp Opin Invest Drugs 9:1079-1096.

Rose K, Goldberg MP, Choi DW (1992) Cytotoxicity in murine neocortical cell culture. Methods Toxicol 1:46-60.

Schall TJ, Bacon K, Toy KJ, Goeddel DV (1990) Selective attraction of monocytes and $\mathrm{T}$ lymphocytes of the memory phenotype by cytokine RANTES. Nature 374:669-671.

Schoepp DD, Jane DE, Monn JA (1999) Pharmacological agents acting at subtypes of metabotropic glutamate receptors. Neuropharmacology 38:1431-1476.

Simpson JE, Newcombe J, Cuzner ML, Woodrofe MN (1998) Expression of monocyte chemoattractant protein-1 and other betachemokines by resident glia and inflammatory cells in multiple sclerosis lesions. J Neuroimmunol 84:238-249.

Sorensen TL, Tani M, Jensen J, Pierce V, Lucchinetti C, Folcik VA, Qin S, Rottmann J, Sellebjerg F, Strieter RM, Frederiksen JL, Ransohoff RM (1999) Expression of specific chemokines and chemokine receptors in the central nervous system of multiple sclerosis patients. J Clin Invest 103:807-815.

Taub DD, Sayer TJ, Carter CR, Ortaldo JR (1995) Alpha and beta chemokines induced NK cell migration and enhance NK-mediated cytolysis. J Immunol 155:3877-3888.

Wells TNC, Power CA, Proudfoot AET (1998) Definition, function and pathophysiological significance of chemokine receptors. Trends Pharmacol Sci 19:376-380.

Zang YC, Halder JB, Samanta AK, Hong J, Rivera VM, Zhang JZ (2001) Regulation of chemokine receptor CCR5 and production of RANTES and MIP-1 alpha by interferon-beta. J Neuroimmunol 112:172-180. 